\title{
FORMAÇÃO DIFERENCIADA EM PESQUISA NOS EGRESSOS DE INICIAÇÃO CIENTÍFICA: IMPLICAÇÕES NO MESTRADO ACADÊMICO
}

\author{
SPECIAL TRAINING IN RESEARCH AMONG STUDENTS \\ WHO COMPLETED SCIENTIFIC RESEARCH INITIATION: \\ IMPLICATIONS FOR ACADEMIC MASTER'S DEGREE \\ FORMACIÓN DIFERENCIADA EN INVESTIGACIÓN EN LOS \\ EGRESADOS DE INICIACIÓN CIENTÍFICA: IMPLICACIONES EN \\ LA MAESTRÍA ACADÉMICA
}

Sarlene Gomes de Souza https://orcid.org/0000-0001-9600-7650

Silvia Maria Nóbrega-Therrien https://orcid.org/0000-0002-8412-8575

Maria Raquel de Carvalho Azevedo https://orcid.org/0000-0002-1587-3520

Samara Moura Barreto de Abreu https://orcid.org/0000-0003-1198-5602

\begin{abstract}
Resumo: O artigo discute as implicações da formação diferenciada em pesquisa, de estudantes egressos da iniciação científica (IC), para seu ingresso nos programas de mestrado. $O$ termo formação diferenciada trata dos processos e resultados da aprendizagem partilhada entre integrantes de grupos de pesquisa e IC. Essa formação de habilidades para a pesquisa e reflexividade crítica é considerada essencial para a aprendizagem profissional e é exigência que recai nos programas de pós-graduação, pois se requer a capacidade de manejo da pesquisa, e a produção própria. O estudo buscou mapear como a seleção em uma instituição de ensino superior no Ceará, revela a presença de alunos oriundos de IC e como o seu desempenho realça a qualidade da formação em pesquisa. O estudo é descritivo, do tipo documental e a abordagem é predominantemente quantitativa. Os dados questionam se egressos de IC partem na seleção acumulando vantagens como currículo ou adequação de projetos de pesquisa às linhas de estudo disponíveis e diante disto, o ingresso precoce
\end{abstract}


destes à pós-graduação parece ser um resultado natural. Esse panorama reclama mudanças e exige novas oportunidades para inclusão de estudantes a formações mais qualificadas em pesquisa.

Palavras-chave: Formação Diferenciada. Formação para a Pesquisa. Iniciação Científica. Mestrado Acadêmico.

\begin{abstract}
This paper discusses the implications of special training in research, among students who completed scientific research initiation (SRI), for their admission to master's degree programs. The term special training refers to learning processes and results shared among members of SRI and research groups. This development of skills for research and critical reflectiveness is considered essential for professional learning and is a recurrent requirement in graduate programs, since they demand the ability to manage research and independent production. The study aimed to map the way in which the selection process in a higher education institution in Ceará reveals the presence of students who came from SRI and how their performance reinforces the quality of research training. The method used was a descriptive, documentary study, and the approach is predominantly quantitative. The data investigate whether students who completed SRI accumulate advantages at the start of the selection, such as curriculum vitae or adjustment of research projects to the available study lines, and, consequently, their early admission to graduate programs seems to be a natural effect. This background calls for changes and requires new opportunities for the inclusion of students in more qualified training in research.
\end{abstract}

Keywords: Special Training. Research Education. Scientific Research Initiation. Academic Master's Degree.

Resumen: El artículo discute las implicaciones de la formación diferenciada en investigación de estudiantes egresados de la iniciación científica (IC) para su ingreso a programas de maestría. El término formación diferenciada se refiere a los procesos y resultados del aprendizaje compartido entre integrantes de grupos de investigación e IC. Se considera que esta formación de habilidades para la investigación y reflexividad crítica es esencial para el aprendizaje profesional y es una exigencia que recae en los programas de posgrado, dado que se requiere la capacidad de manejo de la investigación y la producción propia. El estudio buscó mapear cómo la selección en una institución de educación superior en Ceará revela la presencia de estudiantes procedentes de IC y cómo su desempeño acentúa la calidad de la formación en investigación. El estudio es descriptivo, del tipo documental, y el enfoque es predominantemente cuantitativo. Los datos cuestionan si egresados de IC empiezan la selección acumulando ventajas, como currículum o adecuación de proyectos de investigación a las líneas de estudio disponibles, y, frente a esto, el ingreso temprano de estos estudiantes al posgrado parece ser un resultado natural. Este escenario requiere cambios y exige nuevas oportunidades para la inclusión de estudiantes en formaciones más cualificadas en investigación.

Palabras clave: Formación Diferenciada. Formación para la Investigación. Iniciación Científica. Maestría Académica.

\title{
INTRODUÇÃO
}

A formação diferenciada é fruto de uma experiência vivida no ambiente formativo da universidade por um grupo por demais reduzido de alunos nos programas de iniciação científica e grupos de pesquisa. Essa experiência a que nos referimos decorre de momentos de aprendizagem colaborativa entre professores experientes e alunos de todos os níveis acadêmicos (graduação e pós-graduação) que compartilham de um aprendizado teórico-prático e desenvolvem habilidades que irão refletir na atuação profissional e pessoal dos envolvidos, (NÓBREGA-THERRIEN; ALMEIDA; ANDRADE, 2009). 
Os programas de iniciação científica (IC), neste passo, aparecem como a grande oportunidade de articulação dos alunos de graduação com a vivência em pesquisa científica. Nesse ambiente, o estudante vivencia e experimenta na prática a metodologia que envolve a pesquisa, bem como adquire referencial teórico para a ampliação de sua capacidade crítica e reflexiva, ou seja, "[...] um caminho que o estudante trilha, adquirindo durante seu percurso os instrumentos exigidos para obter êxito no seu trabalho intelectual." (NOBREGA-THERRIEN; CRUZ; ANDRADE, 2009, p. 96). Complementando esse entendimento, Lüdke et al. (2009, p. 20) acentuam que "[...]a participação em uma pesquisa que está sendo realizada constitui a melhor preparação para o futuro pesquisador, em todas as áreas." Ao levarmos em conta a composição multidisciplinar dos grupos, vemos que estudantes de áreas distintas trabalham conjuntamente na produção de conhecimento, buscando resultados com suporte em diversificadas visões.

A oportunidade de ingresso dos estudantes de cursos de graduação nos programas de IC, contudo, é reduzida. Considerando o locus de nossa investigação, a Universidade Estadual do Ceará [UECE] (2016a), que, mesmo sendo considerada a melhor universidade estadual do Norte, Nordeste e Centro-Oeste do Brasil, com relação a indicadores de ensino, inovação, internacionalização, pesquisa e mercado, matriculou 14.684 alunos e ofertou 652 bolsas de iniciação científica no semestre letivo de 2015.2 (UECE, 2016b). Tal significa expressar que apenas $4.4 \%$ de alunos puderam ser premiados com esta oportunidade; e consideramos que aqueles nesta condição tiveram a oportunidade de ter uma formação diferenciada.

Provavelmente, como uma maneira de contornar essa demanda reprimida, nesta mesma instituição, foi criado um programa para a participação voluntária em IC, e a procura por este sinaliza o interesse de estudantes no aprendizado que esses ambientes fomentam, e não apenas no auxílio financeiro das bolsas (SILVA, 2008).

Uma implicação da ausência de Educação científica na graduação é a dificuldade de escrita e direcionamento das pesquisas, quando o discente ingressa em programas de pós-graduação. Para Nobrega-Therrien e Andrade (2009), essa dificuldade contribui para que as produções científicas fiquem aquém do esperado em termos de produção e inovação de conhecimentos.

Os estudantes de pós-graduação, contudo, bem como seus orientadores, devem obrigatoriamente manter um bom nível de produção científica, sob pena de descredenciamento de seus programas. A necessidade da escrita científica, no entanto, para muitos estudantes de pós-graduação, em especial para alunos de mestrado, é uma tarefa difícil de realizar (BIANCHETTI, 2008; FARIAS et al., 2014; FAZENDA, 2010; NOBREGA-THERRIEN; ANDRADE, 2009; PEREIRA; ANDRADE, 2008).

Como, então, é o desenvolvimento de estudantes pós-graduandos que já possuem uma formação diferenciada em pesquisa? Como é o desempenho dos estudantes nas seleções? Denotam maior facilidade em determinada etapa da seleção (prova escrita, projeto, currículo, entrevista)? Como é a produção científica do estudante durante os 24 meses de duração do curso? É em torno dessas preocupações que delineamos os objetivos desta investigação, detalhados sequentemente. 


\section{OBJETIVOS:}

Buscamos, com este estudo, analisar as implicações da formação diferenciada em pesquisa em estudantes da graduação que foram bolsistas de iniciação científica e, consequentemente, membros de grupos de pesquisa e como ela se manifesta na seleção para mestrado acadêmico. Mais especificamente, determinar as diferenças no processo seletivo em curso de mestrado acadêmico com relação aos inscritos e aprovados com ou sem formação diferenciada em pesquisa e ainda, mapear a produção científica de estudantes egressos e não egressos de IC no mestrado acadêmico durante o período do curso.

Pressupostos, de saída, que estes estudantes (bolsistas) ao participarem dos referidos grupos adquirem uma formação que identificamos como 'diferenciada' e nesse sentido, esta facilita o acesso e desenvolvimento destes a programas de pós-graduação. Expresso de outra maneira, entendemos que a formação adquirida em grupos de pesquisa por alunos participantes de programas de iniciação cientifica se manifesta de modo positivo, posteriormente, quando nos programas de pós-graduação stricto sensu.

\section{MÉTODOS:}

Esta pesquisa caracteriza-se como estudo descritivo, do tipo documental e de abordagem predominantemente quantitativa, por via da qual investigamos quais as implicações da experiência em atividades de pesquisa, por via da iniciação científica por alunos da graduação, na seleção para os cursos de mestrado acadêmico e na produção científica.

A pesquisa documental tem como característica a pouca presença e intervenção da realidade analisada pelo pesquisador, além de permitir maior amplitude temporal na compreensão de fenômenos; ou seja, é possível analisar a trajetória / o desenvolvimento de grupos no decorrer do tempo e examinar acontecimentos cujos envolvidos não estejam mais disponíveis. Embora a busca documental requeira pouca influência do investigador na realidade estudada, por outro lado, a base teórica que fundamenta o pesquisador influenciará significativamente na escolha dos documentos, na sua organização e sistematização e, consequentemente, na análise dos resultados.

Para garantir a representatividade da realidade estudada, votamos pela inclusão de documentos oriundos dos programas de pós-graduação. Eles representam os resultados oficiais das seleções estudadas por nós. Para a identificação da produção bibliográfica, utilizamos o currículo disponibilizado na Plataforma Lattes do Conselho Nacional de Desenvolvimento Científico e Tecnológico (CNPq).

A escolha pelos cursos da UECE se deu por três fatores principais: ser a universidade estadual que mais matricula e titula mestres no nordeste do País ${ }^{1}$, ter sido considerada por

1 No ano de 2015 a UECE foi responsável por matricular 594 estudantes do total de 121.451 matriculados em mestrados acadêmicos no País, tendo titulado 299 mestres dos 46.517 diplomados em todo o País. Se compararmos os mesmos dados com as demais universidades públicas estaduais do Nordeste do País, a 
seis vezes a melhor academia estadual do Norte, Nordeste e Centro-Oeste do País, fato também mencionado na introdução deste ensaio, e é o local onde desenvolvemos atividades como docentes ou discentes, com isso, possuímos maior aproximação para coletar dados.

O recorte geográfico pelos cursos sediados em Fortaleza se deu por: (i) estes serem os cursos mais antigos e mais consolidados da Universidade e (ii) ter a maior densidade de cursos, ou seja, o maior número de cursos agrupados em uma menor área, fator crucial para a viabilidade da pesquisa, uma vez que teríamos de visitar todas secretarias destes cursos para aquisição de dados.

No ano de coleta deste estudo (2016-2017), existiam cadastrados no sítio eletrônico da Pró-Reitoria de Pós-Graduação e Pesquisa (PROPGPq) da UECE 15 cursos de Mestrado Acadêmico (MA) sediados em Fortaleza (UECE, 2016c). Alguns deles estão em programas de pós-graduação (PPG), pois possuem cursos de mestrado e doutorado, e outros são cursos de MA. A seguir, o quadro-síntese dos cursos convidados a participarem do estudo.

Quadro 1 - Relação de cursos de mestrado acadêmico situados no Campos de Fortaleza que estão no site da PROPGPq da UECE em 2016

\begin{tabular}{|c|c|c|c|c|c|}
\hline Centro & Nome do Curso & Situação & $\begin{array}{c}\text { Conceito } \\
\text { CAPES } \\
2013 \\
\end{array}$ & $\begin{array}{c}\text { Conceito } \\
\text { CAPES } \\
2017\end{array}$ & Criação \\
\hline \multirow{3}{*}{$\begin{array}{l}\text { Ciências da } \\
\text { Saúde }\end{array}$} & $\begin{array}{l}\text { Cuidados Clínicos em } \\
\text { Enfermagem e Saúde }\end{array}$ & PPG & 4 & 5 & $\begin{array}{c}\text { Criado em } 2003 \\
\text { Recomendado } 2004\end{array}$ \\
\hline & Saúde Coletiva & PPG & 4 & 4 & $\begin{array}{c}\text { Criado em } 1993 \\
\text { Recomendado } 1994\end{array}$ \\
\hline & Nutrição e Saúde & MA & 3 & 3 & Recomendado 2010 \\
\hline \multirow{4}{*}{$\begin{array}{l}\text { Ciências e Tec- } \\
\text { nologias }\end{array}$} & Ciência da Computação & MA & 3 & 3 & $\begin{array}{c}\text { Criado em } 2005 \\
\text { Recomendado } 2006\end{array}$ \\
\hline & Ciências Físicas Aplicadas & MA & 3 & 3 & Recomendado 2004 \\
\hline & Geografia & PPG & 4 & 4 & $\begin{array}{c}\text { Criado em } 1995 \\
\text { Recomendado } 2010\end{array}$ \\
\hline & Recursos Naturais & PPG & & 4 & Recomendado 2012 \\
\hline Educação & Educação & PPG & 4 & 5 & $\begin{array}{c}\text { Criado em } 2002 \\
\text { Recomendado } 2003\end{array}$ \\
\hline \multirow{2}{*}{$\begin{array}{c}\text { Estudos Sociais } \\
\text { Aplicados }\end{array}$} & Administração & PPG & 4 & 4 & Recomendado 2004 \\
\hline & $\begin{array}{c}\text { Serviço Social, Trabalho e } \\
\text { Questão Social }\end{array}$ & PPG & 3 & 4 & Recomendado 2011 \\
\hline \multirow{4}{*}{ Humanidades } & Filosofia & MA & 3 & 2 & $\begin{array}{c}\text { Criado em } 1998 \\
\text { Recomendado } 2004\end{array}$ \\
\hline & História e Culturas & MA & 3 & 2 & $\begin{array}{c}\text { Criado em } 2006 \\
\text { Recomendado } 2006\end{array}$ \\
\hline & Linguística Aplicada & PPG & 4 & 5 & $\begin{array}{c}\text { Criado em } 1997 \\
\text { Recomendado } 2001\end{array}$ \\
\hline & Sociologia & PPG & 4 & 4 & $\begin{array}{c}\text { Criado em } 2000 \\
\text { Recomendado } 2002\end{array}$ \\
\hline
\end{tabular}

UECE aparece com os maiores números absolutos. SISTEMA DE INFORMAÇÕES GEORREFERENCIADAS [GEOCAPES] (2017). 


\begin{tabular}{|c|c|c|c|c|c|}
\hline $\begin{array}{c}\text { Faculdade de } \\
\text { Veterinária }\end{array}$ & Ciências Veterinárias & PPG & 6 & 6 & $\begin{array}{c}\text { Criado em 1990 } \\
\text { Recomendado 2000 }\end{array}$ \\
\hline
\end{tabular}

Fonte: Elaboração própria com base no site do PROPGPq UECE e Plataforma Sucupira da CAPES.

Para melhor compreensão, definimos que doravante todos os cursos de MA independentemente de estarem inseridos em PPG ou não, denominar-se-ão pela dicção curso ou Mestrado Acadêmico (MA) seguido pelo nome.

Para o desenvolvimento deste estudo, no primeiro momento, estariam incluídos todos os candidatos que concorreram à seleção, em 2014, de mestrados acadêmicos de todos os 15 cursos sediados em Fortaleza da Universidade Estadual do Ceará. As secretarias dos cursos deveriam entregar seus documentos oficiais até o final do mês de outubro de 2017. Portanto, estariam excluídos os cursos que não entregassem os documentos em tempo hábil e, de posse dos documentos, ainda excluímos: (i) alunos oriundos de outros países, com processo seletivo diferente; (ii) alunos cujo nome não permitisse a identificação no currículo da Plataforma Lattes².

No segundo momento, estariam incluídos todos os alunos matriculados nas turmas 2015 de mestrado acadêmico cujo curso disponibilizasse a lista em sítio de internet oficial ou que enviasse a lista dos alunos para nós. Estariam de fora cursos que não entregassem a documentação no prazo e discente com o nome não identificado na Plataforma Lattes.

Na primeira etapa, que consistiu na avaliação do desempenho no processo seletivo buscamos por elementos da formação diferenciada em pesquisa, repercutindo na seleção para o Mestrado Acadêmico (MA). Inicialmente, foi realizada uma busca no sítio de internet oficial de cada curso da UECE situados em Fortaleza. Caso as informações não estivessem disponíveis, seria efetuado o contato com a coordenação do curso por correio eletrônico e, ainda, por meio presencial. Para esse momento da pesquisa, não contamos com os dados de apenas dois cursos: MA em Ciências da Computação, que, segundo a secretaria, eles se desfazem da relação dos inscritos após as seleções, e MA em Recursos Naturais, que não deixa disponíveis tais resultados no sítio da internet e não respondeu aos contatos via e-mail por nós realizados.

No caso dos cursos que também disponibilizavam os resultados parciais de cada etapa do processo seletivo (resultado de prova escrita, análise de currículo, exame de projeto e entrevista), foi possível identificar como se dá a diferença entre egressos e não egressos nas distintas etapas seletivas. Os cursos que dispunham dessas informações eram: MA em Saúde Coletiva, MA em Enfermagem e Cuidados Clínicos, MA em Educação e MA em Filosofia.

Após a coleta da lista contendo inscritos para o processo seletivo, resultados parciais e resultado final dos cursos participantes deste experimento, foi criada para cada curso uma pasta no software Microsoft Excel 2013® com a lista nominal dos candidatos inscritos. Em seguida, consultamos a Plataforma Lattes e buscamos as informações de maneira individual de cada candidato à procura de identificação deste como oriundo ou não de IC. Em caso positivo ou negativo eram classificados como IC (oriundos) e NIC (não oriundos).

2 Por exemplo: busca de nomes que resultasse em mais de 100 registros. 
Eram considerados participantes de IC discentes que atendessem a pelo menos um dos seguintes critérios: (i) ser bolsista de agências de fomentos em IC; (ii) ser voluntário em programas de IC e (iii) indicar que participou de projetos de pesquisa no período da graduação. Foram identificados nesse período 729 estudantes participantes da pesquisa.

Na segunda etapa, que consistiu no mapeamento da produção científica durante o mestrado. Foram analisadas as produções que estavam no Currículo Lattes de todos os discentes aprovados nas seleções 2014 e que compuseram as turmas 2015 dos cursos de mestrado acadêmico. Neste mapeamento, foram identificadas: publicações em periódicos e seu conceito Qualis $^{3}$ na área de concentração de seus respectivos cursos, resumos, resumos expandidos, trabalhos completos, apresentação de trabalhos e capítulos de livros. Após essa cartografia, iniciamos a observação e as analises sobre os egressos de Iniciação Científica (IC) e os não egressos de Iniciação Científica (NIC).

Apenas dois cursos não disponibilizaram on-line ou enviaram a lista dos alunos matriculados: MA em Recursos Naturais e MA em Filosofia. Com os alunos já catalogados em IC e NIC, fomos novamente ao Currículo Lattes e identificamos a produção bibliográfica de cada discente. Elaboramos quadros para organização dos dados no software Microsoft Excel $2013 \AA$, que obedeceram à seguinte ordem: resumos, resumos expandidos, trabalhos completos, apresentação de trabalhos, capítulo de livros e publicações em periódicos. Para identificação do Qualis-Periódicos recorremos aos dados referentes à classificação quadrienal 2013 -2016. Só registramos atividades que estivessem dentro do recorte temporal 2015 a 2017, pois queríamos o recorte relativo ao período do curso de mestrado. Foram analisados os Currículos Lattes referente à produção científica de 215 discentes (correspondem apenas aos alunos aprovados e matriculados, na etapa anterior foram analisados os alunos inscritos nas seleções).

Para a análise dos dados, todos os dados foram organizados e expressos em tabelas e gráficos, utilizando-se do software Microsoft Excel 2013®. Na primeira etapa, foram calculados o número absoluto e a frequência relativa de IC e NIC entre os candidatos inscritos e aprovados nas seleções de cada curso. Também restaram calculados o número absoluto e a frequência relativa de IC e NIC em cada um dos períodos parciais dos cursos que também dispuseram dessas informações. Os dados foram expressos em porcentagem e foi elaborado um gráfico para se proceder às discussões e analises com base em discente IC e NIC entre os distintos cursos.

Na segunda etapa, foi calculada a média de artigos, resumos, resumos expandidos, trabalhos completos, apresentação de trabalhos e capítulos de livros entre alunos IC e NIC para cada curso. A análise da média de artigos foi mais bem avaliada ao estratificar os artigos de acordo com seus conceitos Qualis, sendo criado quatro estratos para análise - A1 a A2, B1 a B3, B4 a C - sem conceito Qualis. Também foram feitos gráficos para comparar as médias encontradas em cada curso, divididos entre IC e NIC.

3 Sistema utilizado para categorizar a produção científica dos programas de pós-graduação no tocante à produção em periódicos. Para saber mais, consultar sítio eletrônico da Plataforma Sucupira https://sucupira. capes.gov.br/sucupira/public/index.xhtml. 
Esta pesquisa foi submetida ao Comitê de Ética em Pesquisa (CEP) da UECE e obteve aprovação sob o número CAAE 69616017.6.0000.5534.

Entendemos que toda pesquisa oferece riscos aos participantes, esta, em particular, por constituir um estudo do tipo documental, oferece perigos mínimos aos participantes, pois utilizamos dados disponíveis em sítios de internet, e, além do mais, nenhum discente foi identificado nesse estudo.

Temos ciência da Resolução 510/2016 do Conselho Nacional de Saúde e utilizamos nossos dados de modo ético e respeitoso.

\section{RESULTADOS E DISCUSSÃO}

\section{Processo seletivo}

Há um entendimento recorrente do fato de que alunos provenientes ou participantes, durante a graduação, de programas de iniciação cientifica conseguem com maior brevidade ter acesso a programas de pós-graduação, quando de seus processos seletivos (COSTA, 2012; LIMA, 2016). Entender e estender essa compreensão em ultrapasse a esse acesso, e em busca das implicações do que consideramos a participação em uma formação diferenciada, nos persuade a percorrer o caminho de egresso de IC, nos cursos de mestrado acadêmico da UECE.

Inicialmente, nos voltamos ao processo seletivo de cursos de mestrado acadêmico da UECE, realizado no ano de 2014. Identificar qual o perfil de inscritos e aprovados com relação a participação em IC ou não foi nossa primeira intenção. A seguir, vejamos a tabela contendo o resultado.

Tabela 1 - Números absolutos (n) e frequência relativa (\%) de discentes inscritos e aprovados para os cursos de mestrado acadêmico da UECE sediados em Fortaleza no ano de 2014

\begin{tabular}{|c|c|c|c|c|c|c|c|c|c|c|}
\hline \multirow{3}{*}{ Curso } & \multicolumn{5}{|c|}{ Candidatos inscritos } & \multicolumn{5}{|c|}{ Candidatos aprovados } \\
\hline & \multicolumn{2}{|c|}{ IC } & \multicolumn{2}{|c|}{ NIC } & \multirow[t]{2}{*}{ Total } & \multicolumn{2}{|c|}{ IC } & \multicolumn{2}{|c|}{ NIC } & \multirow{2}{*}{$\begin{array}{c}\text { Total } \\
\mathbf{n}\end{array}$} \\
\hline & $\mathbf{n}$ & $\%$ & $\mathbf{n}$ & $\%$ & & $\mathbf{n}$ & $\%$ & $\mathbf{n}$ & $\%$ & \\
\hline Cuidados Clínicos em Enfermagem e Saúde & 28 & $37,84 \%$ & 46 & $62,16 \%$ & 74 & 9 & $47,37 \%$ & 10 & $52,63 \%$ & 19 \\
\hline Nutrição e Saúde & 16 & $64,00 \%$ & 9 & $36,00 \%$ & 25 & 10 & $76,92 \%$ & 3 & $23,08 \%$ & 13 \\
\hline Saúde Coletiva & 21 & $22,34 \%$ & 73 & $77,66 \%$ & 94 & 9 & $32,14 \%$ & 19 & $67,86 \%$ & 28 \\
\hline Ciências Físicas Aplicadas & 4 & $30,77 \%$ & 9 & $69,23 \%$ & 13 & 3 & $33,33 \%$ & 6 & $66,67 \%$ & 9 \\
\hline Geografia & - & & - & - & & 10 & $55,56 \%$ & 8 & $44,44 \%$ & 18 \\
\hline Educação & 27 & $12,39 \%$ & 191 & $87,61 \%$ & 218 & 9 & $30,00 \%$ & 21 & $70,00 \%$ & 30 \\
\hline Administração & 6 & $18,75 \%$ & 26 & $81,25 \%$ & 32 & 5 & $31,25 \%$ & 11 & $68,75 \%$ & 16 \\
\hline Serviço Social, Trabalho e Questão Social & 5 & $12,20 \%$ & 36 & $87,80 \%$ & 41 & 3 & $25,00 \%$ & 9 & $75,00 \%$ & 12 \\
\hline Filosofia & 11 & $23,91 \%$ & 35 & $76,09 \%$ & 46 & 8 & $53,33 \%$ & 7 & $46,67 \%$ & 15 \\
\hline História e Culturas & 10 & $16,95 \%$ & 49 & $83,05 \%$ & 59 & 8 & $47,06 \%$ & 9 & $52,94 \%$ & 15 \\
\hline Linguística Aplicada & 10 & $15,38 \%$ & 55 & $84,62 \%$ & 65 & 6 & $33,33 \%$ & 12 & $66,67 \%$ & 18 \\
\hline Sociologia & 10 & $19,23 \%$ & 42 & $80,77 \%$ & 52 & 7 & $46,67 \%$ & 8 & $53,33 \%$ & 15 \\
\hline Ciências Veterinárias & 9 & $90,00 \%$ & 1 & $10,00 \%$ & 10 & 6 & $100,00 \%$ & 0 & $0,00 \%$ & 6 \\
\hline TOTAL & 157 & $21,54 \%$ & 572 & $78,46 \%$ & 729 & 93 & $43,06 \%$ & 123 & $56,94 \%$ & 214 \\
\hline
\end{tabular}

Fonte: Elaboração própria, com suporte nos resultados oficiais das seleções dos cursos participantes e Currículo Lattes. 
Analisando a coluna referente ao número de inscritos, é possível perceber a diferenciação entre os cursos na tabela 1. Alguns programas têm pequena procura, como por exemplo, o MA em Ciências Veterinárias, que teve dez inscritos, e o MA em Ciências Físicas Aplicadas, com 13 postulantes. O MA em Educação, por sua vez, obteve procura significativa, se comparada aos demais, registrando 218 inscritos no ano de 2014.

Esse fato nos impele a indagar: por que é um curso com alta procura? É um curso fora o qual todas as áreas ou formações acadêmicas de certo modo, podem convergir. Não podemos esquecer de que também é um curso procurado por profissionais da Educação Básica, uma vez que possui sua área de concentração ou carro forte a formação de professores. Essa busca pela qualificação no patim da pós-graduação, além de ser, em sua maioria, um intento e necessidade dos docentes, sejam eles provenientes de escolas ou universidades, responde também aos planos de cargos e carreiras destes profissionais, com aumento salarial para docentes, realizam cursos com o status de stricto sensu.

Interessante, também, é o fato de que O MA em Educação estimula a vinda de docentes, atribuindo na seleção pontuações na etapa de avaliação do currículo, que podem chegar até $20 \%$ do peso total da etapa, pois é atribuída a marca de até 1.6 por experiência de ensino e destinando o valor de até 0.5 por experiência técnico-pedagógica na Educação (UECE, 2017). A literatura é recorrente em apontar os ganhos nesse tipo de qualificação. Autores como Lüdke, Rodrigues, e Portella (2012) assinalam sobre a importância de cursos de mestrado acadêmico destinados ao desenvolvimento de profissionais do magistério, e, com o Plano Nacional da Pós-Graduação 2005 - 2010, os profissionais da Educação Básica receberam uma contemplação evidente nas políticas educativas no contexto de pós-graduação. Além de constituir evidência no Plano Nacional de Educação (PNE) em 2014, no âmbito da qualificação docente.

Dado interessante é evidenciado quando analisamos o perfil - relativo à participação ou não em IC, dos alunos que buscam os cursos. Observamos, então, que o MA em Educação tem o segundo menor número de inscritos oriundos de IC, com $12.39 \%$. Está na frente apenas do MA em Serviço Social, Trabalho e Questão Social, com $12.20 \%$. No extremo oposto, registramos o MA em Nutrição e Saúde, com $64 \%$ dos inscritos egressos de IC e o MA em Ciências Veterinárias com 90\%.

Esse resultado, em parte, foi identificado na pesquisa realizada por Velloso e Velho (2001), publicada há mais de 15 anos, quando traçaram o perfil de mestres brasileiros por área do conhecimento, no que é pertinente à composição das turmas de mestrado por egressos de IC. Nesta pesquisa, os cursos das Ciências Agrárias (área na qual a Ciência Veterinária está inserida) estão inscritos nas três primeiras áreas com maior predominância de egressos de IC (29.4\%), ficando atrás de cursos das Ciências Exatas e da Terra (55.6\%) e Engenharias (31.8\%) - dado que se confirma. Divergindo de nosso achado, no entanto, no estudo de Velloso e Velho (2001) os re- 
sultados relacionados aos cursos da área da Saúde (na qual a Nutrição se inscreve) indicam os menores percentuais de egressos de IC, compondo as turmas de mestrado $(9.4 \%)$.

Em outra pesquisa, similar à desses autores, mais recente, e realizada por Lima (2016) no contexto da Universidade Federal do Rio Grande do Sul, também havia a predominância de alunos egressos de IC nos cursos de pós-graduação da grande área de Ciências Agrárias, bem como, nos das Ciências Biológicas e das Ciências Exatas e da Terra, bem assim, cursos da área Multidisciplinar. Nos cursos das Ciências da Saúde, Ciências Humanas e Ciências Sociais Aplicadas, os dados eram o oposto, uma vez que havia neles a predominância de NIC (LIMA, 2016).

Os dois estudos mencionados a pouco não analisaram o perfil dos inscritos nas seleções e sim dos aprovados. No nosso estudo, se nos reportarmos apenas aos aprovados, o MA em Ciências Veterinárias tem a totalidade da turma pois composto pelo grupo IC, seguido pelo MA Nutrição e Saúde, com 76.92\%, depois o MA em Geografia, pertencente as Ciências Exatas e da Terra, com $55.56 \%$, e, por fim, o MA em Filosofia, da grande área de Humanidades, com 53.33\%.

Com efeito, nosso estudo soma evidências de que cursos das Ciências Agrárias e Ciências Exatas e da Terra têm sucesso em suas ações de IC no sentido de encaminhar seus egressos para a continuidade dos estudos no plano da pós-graduação. Essa relação é benéfica, uma vez que a articulação das dissertações atreladas aos projetos de pesquisas dos orientadores resulta em melhor formação e maior produtividade dos alunos nos mestrados acadêmicos (VELLOSO; VELHO, 2001). Nesse sentido, quando o aluno já está familiarizado com o projeto de pesquisa do orientador desde a graduação, a tendência é de que o trabalho de ambos seja facilitado na pós-graduação.

Outra maneira de percebemos a relação entre inscritos e aprovados por egressos e não egressos de IC é por meio do gráfico elaborado por nós, expressa na sequência. 
Sarlene Gomes de Souza | Silvia Maria Nóbrega-Therrien Maria Raquel de Carvalho Azevedo | Samara Moura Barreto de Abreu

Gráfico 1 - Relação de inscritos e aprovados por cursos de mestrado acadêmico da UECE sediados em Fortaleza em 2014

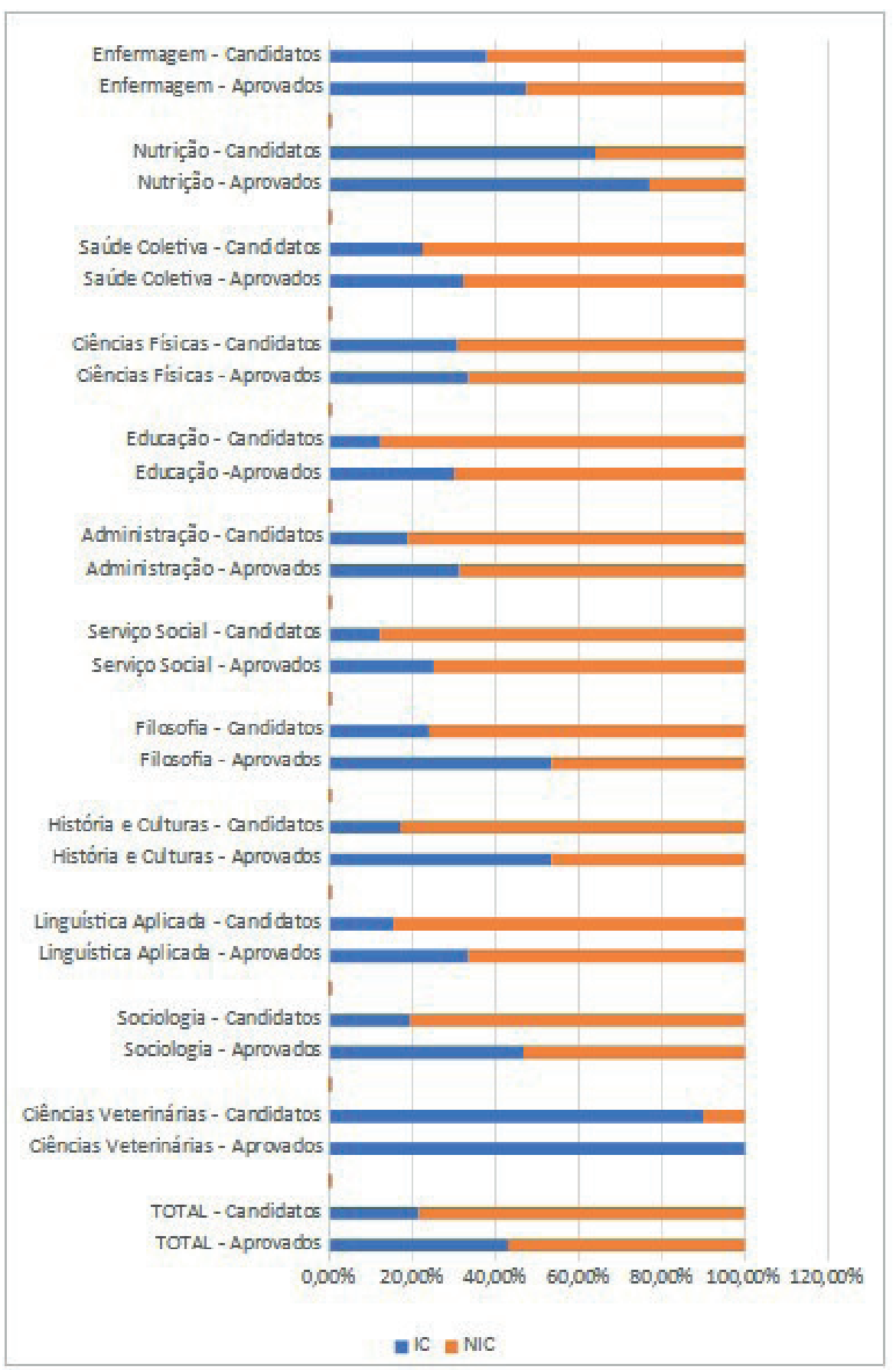

Fonte: Elaboração própria, com suporte nos documentos oficias dos cursos participantes.

Evidenciamos ante os achados que discentes do grupo IC têm maiores taxas de aprovação quando comparados com NIC. Para buscar compreender se existe uma etapa específica em que o grupo IC se sobrepõe, analisamos o processo seletivo por partes, pois, nos foram disponibilizados os resultados parciais de quatro cursos. Consoante está a seguir no gráfico de número dois. 
Gráfico 2 - Comparação entre etapas do processo seletivo por cursos de mestrado acadêmico da UECE sediados em Fortaleza em 2014, por grupo IC e NIC

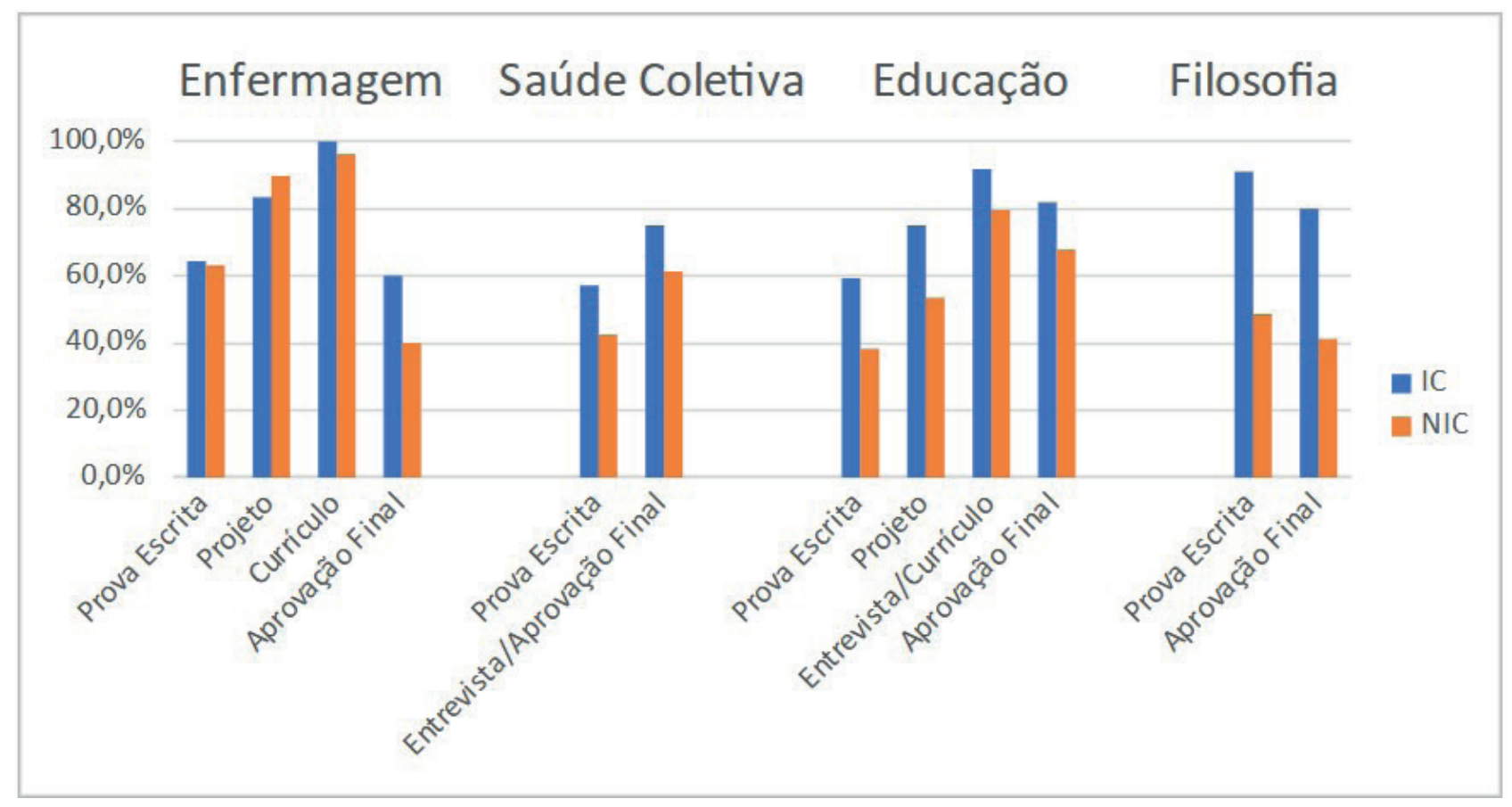

Fonte: Elaboração própria, com suporte nos documentos oficias dos cursos participantes.

Nos cursos MA em Filosofia, MA em Educação e MA em Saúde Coletiva, percebemos aumento gradual de aprovação do grupo IC em cada etapa do processo seletivo, culminando com a aprovação. Em parte, esse resultado nos surpreende, pois entrevimos a hipótese de que os discentes IC, por terem uma produção bibliográfica mais sistematizada na graduação e por estarem mais familiarizados com linhas de pesquisas de orientadores, seria evidente a aprovação nas etapas de análises de projetos de pesquisa e currículo. Os resultados apontaram, no entanto, que, além dessas etapas citadas, eles também tiveram maiores aprovações parciais na prova escrita.

Tal consequência pode ser explicada pelo fato de já sabermos que discentes do grupo IC buscam a pós-graduação num período menor que discentes NIC (VELLOSO; VELHO, 2001; COSTA, 2013; LIMA, 2016), O grupo IC, portanto, estaria num ritmo sistematizado de estudos e produção escrita. Para o grupo NIC, o tempo entre o término da graduação e início da pós-graduação pode levar em média dez anos (FERREIRA; MORRAYE, 2013), fator que, entendemos, dificulta seu acesso em habilidades investigativas, quando aumenta muitas vezes em experiência, sobretudo na docência.

No MA em Cuidados Clínicos em Enfermagem e Saúde, percebemos que não houve um crescimento do grupo IC no quesito projeto. No resultado final, entretanto, após a análise de currículo, permaneceu um aumento do grupo IC. Mais estudos seriam necessários para elucidar esse ponto. 


\section{PRODUÇÃO CIENTÍFICA}

O segundo objetivo específico deste estudo foi mapear a produção científica de estudantes egressos e não egressos de IC no mestrado acadêmico durante o período do curso. Ressaltamos que, no Currículo Lattes e em alguns estudos, a produção científica escrita é denominada produção bibliográfica. Nesse sentido, para este relatório de pesquisa, produção científica e produção bibliográfica devem ser entendidas como expressões sinônimas e referem-se à produção escrita dos discentes.

Nessa etapa das análises, foram examinados apenas os discentes aprovados e matriculados, oriundos da seleção 2014, e que compuseram as turmas de MA 2015 dos referidos programas da UECE situados em Fortaleza.

Pressupusemos que o grupo IC teria mais volume, bem como mais qualidade de produção. A seguir mostraremos a tabela indicando a média de produtos entre os grupos de cada curso, com relação a resumo simples, resumo expandido, trabalho completo, apresentação de trabalho, capítulo de livro e produção em periódico. resolvemos não incluir os resultados do MA em Ciências Veterinárias, uma vez que não há discentes do grupo NIC para efetuar a comparação.

Tabela 2 - Média de produtos dos discentes analisados nos curso de mestrado acadêmico da UECE sediados em Fortaleza turmas 2015

\begin{tabular}{|c|c|c|c|c|c|c|c|c|c|c|c|c|}
\hline \multirow[t]{2}{*}{ Cursos } & \multicolumn{2}{|c|}{ Resumo } & \multicolumn{2}{|c|}{$\begin{array}{c}\text { Resumo } \\
\text { Expandido }\end{array}$} & \multicolumn{2}{|c|}{$\begin{array}{l}\text { Trabalho } \\
\text { Completo }\end{array}$} & \multicolumn{2}{|c|}{$\begin{array}{l}\text { Apresentação } \\
\text { de Trabalhos }\end{array}$} & \multicolumn{2}{|c|}{$\begin{array}{l}\text { Capítulo de } \\
\text { Livros }\end{array}$} & \multicolumn{2}{|c|}{$\begin{array}{l}\text { Publicação } \\
\text { em } \\
\text { periódicos }\end{array}$} \\
\hline & IC & $\mathrm{NIC}$ & IC & $\mathrm{NIC}$ & IC & $\mathrm{NIC}$ & IC & $\mathrm{NIC}$ & IC & $\mathrm{NIC}$ & IC & $\mathrm{NIC}$ \\
\hline $\begin{array}{c}\text { Cuidados Clínicos } \\
\text { em Enfermagem }\end{array}$ & 9,33 & 9,40 & 1,44 & 1,00 & 2,78 & 2,00 & 5,67 & 7,50 & 0,44 & 0,50 & 3,78 & 2,10 \\
\hline Saúde Coletiva & 2,33 & 5,14 & 1,22 & 1,67 & 0,89 & - & 4,44 & 4,00 & 3,00 & 1,24 & 0,56 & 0,48 \\
\hline Nutrição e Saúde & 3,20 & - & 0,50 & 0,33 & 0,20 & - & 4,80 & 0,33 & 0,70 & - & 0,80 & - \\
\hline $\begin{array}{c}\text { Ciências Físicas } \\
\text { Aplicadas }\end{array}$ & 0,33 & 0,50 & - & - & - & - & 0,67 & 4,33 & - & - & 1,33 & 0,17 \\
\hline Geografia & 0,70 & 0,25 & 0,20 & - & 0,10 & 1,00 & 1,80 & 1,75 & - & - & 0,70 & 0,63 \\
\hline Educação & 1,56 & 1,95 & 1,33 & 0,80 & 2,44 & 3,15 & 3,00 & 4,35 & 1,44 & 0,10 & 0,78 & 0,55 \\
\hline Administração & 0,80 & 0,30 & - & - & 1,80 & 2,40 & 2,40 & 2,50 & - & 0,20 & 1,40 & 1,80 \\
\hline Serviço Social & 3,67 & 1,34 & - & - & 4,67 & 2,02 & 4,33 & 1,99 & - & 0,02 & 0,33 & 0,47 \\
\hline História e Culturas & 1,13 & 1,14 & 0,13 & - & 1,75 & 1,71 & 3,00 & 6,86 & 0,25 & 0,14 & 0,25 & 0,29 \\
\hline $\begin{array}{l}\text { Linguística } \\
\text { Aplicada }\end{array}$ & 1,67 & 0,67 & - & 0,08 & 0,67 & 0,50 & 4,83 & 6,58 & 0,17 & 0,08 & 0,83 & 2,08 \\
\hline Sociologia & 0,43 & - & 0,14 & 0,13 & 1,14 & 0,25 & 3,29 & 1,63 & - & - & 0,57 & - \\
\hline Computação & - & 0,56 & - & - & - & 0,22 & 0,20 & 0,11 & 0,20 & 1,56 & 0,60 & 1,22 \\
\hline Media Geral & 2,33 & 2,11 & 0,54 & 0,49 & 1,27 & 1,15 & 3,43 & 3,60 & 0,52 & 0,48 & 1,04 & 0,80 \\
\hline
\end{tabular}

Fonte: Elaboração própria, com base na Plataforma Lattes dos discentes analisados. 
Podemos observar na tabela 2, com relação aos resumos, que, na metade dos 12 cursos analisados, o grupo IC teve média maior de produtos. Isto nos remete à atenção para o fato de que dois cursos da área da saúde - o MA em Cuidados Clínicos em Enfermagem e Saúde e MA em Saúde Coletiva - exprimem significativa diferença com relação aos demais cursos, entrementes, o grupo NIC foi responsável pela maior parte de produção deles, com a média de 9,40 e 5,14 resumos simples, respectivamente.

Volpato (2004) comenta acerca da crescente opção de pesquisadores brasileiros por enviar resumos para congressos em razão da facilidade de elaboração de um pequeno texto. Geralmente, esses escritos são focados nos resultados, não havendo espaço para análises ou posicionamentos dos pesquisadores. Sabemos que as normas de elaboração dos congressos variam conforme o campo de origem. Por exemplo, em Educação, destacamos o limite de três autores em cada resumo e, quando o trabalho é aceito, deve-se obrigatoriamente submeter o escrito completo, elevando a dificuldade de elaboração dos textos.

Com relação aos resumos expandidos, embora sejam produtos que permitam maior quantidade de informação, ainda são ensaios de fácil produção. Analisando os resumos expandidos, depreendemos que os discentes em todos os cursos mantêm média baixa de publicações, abaixo de dois no período de mestrado. Já os trabalhos completos são textos maiores, em que a quantidade de páginas necessárias pode variar de acordo com o evento, mas via de regra, ficando em torno de doze. É possível perceber que a produção desse modelo de foi mais recorrente no grupo IC do MA em Serviço Social Trabalho e Questão Social, e no grupo NIC do MA em Educação, ambos das áreas de Ciências Humanas.

Nos quesitos resumos, resumos expandidos e trabalhos completos, evidenciamos o fato de que, embora se registre variação nas grandes áreas, na maioria dos cursos, o grupo IC mantém maior volume desses produtos. Lima (2016) também evidenciou no seu estudo que o grupo IC, na maior parte das grandes áreas estudadas por ela, se sobressaiu com maiores médias de produções, fato indicativo de que a grande área não influencia nos resultados, e sim a formação diferenciada do discente adquirida em IC. Nossos achados corroboram esta afirmação.

No pertinente à apresentação de trabalhos, em cinco dos 12 cursos estudados, o grupo NIC manteve média maior do que o IC. Foram nos cursos MA em Física Aplicada, MA em Educação, MA em Administração, MA em História e Culturas e MA em Linguística Aplicada. Esse quesito foi o único em que a média total (sem divisão por cursos) do grupo NIC foi maior do que a média do grupo IC. Essa realidade conduz-nos a indagar: por que esses alunos não submeteram esses trabalhos a periódicos? A pergunta tem pertinência, no nosso sentir, haja visto o fato de que publicações dessa natureza são com insistência estimuladas pelos orientadores e cursos de mestrado, pois consiste em um dos quesitos de avaliação dos cursos pela CAPES.

Os dois últimos quesitos, capítulo de livro e publicação em periódico, ao nosso ver, são os veículos que mais requerem habilidades para a escrita, por serem textos mais com- 
pletos, com a coesão e o posicionamento teórico-crítico do pesquisador. Na modalidade artigo para periódicos, o texto é avaliado por uma comissão científica para, então, o trabaIho ser aceito. Esse tipo de veículo de informação científica requer dos autores um escrito expresso concisamente e necessita de análises, reflexões e considerações elaboradas pelos pesquisadores. Evidenciamos, portanto, o fato de que para a elaboração de textos dessa natureza, são requeridas habilidades, e estas são especificamente trabalhadas em ambientes de IC.

Oliveira (2013), queria compreender no que consistia a formação diferenciada obtida em IC. Ela buscou evidências de que esses ambientes proporcionavam, além de uma formação técnica (mais relacionada a execução de pesquisas) um preparo teórico, ou seja, ampliação das bases epistemológicas dos bolsistas. Oliveira (2013) concluiu que há uma proporcionalidade de atividades, destinadas aos estudantes, de cunho técnico/prático e de conteúdo epistemológico/teórico, apontando para a formação diferenciada obtida pelos bolsistas nesses locais; e essa formação facilita o desenvolvimento de pesquisas e auxilia a produção escrita.

Com relação a capítulos de livros, o curso cujo grupo NIC teve média maior foi o MA em Ciências da Computação, ao passo que, nos demais, o grupo IC se sobressaiu. Vale ressaltar ainda o desempenho dos discente IC do MA em Saúde Coletiva, com média de três capítulos de livros por discente, enquanto o segundo curso com maior produção de capítulo de livro foi o MA em Educação, com 1,44 por discente do grupo IC.

No estudo de Batista, Nobrega-Therrien e Almeida (2009), ao investigarem as dificuldades e facilidades na escrita científica dos discentes de pós-graduação de um curso da área da saúde, sobrou evidenciado pelas autoras com amparo nas falas dos discentes, o fato de que o tempo curto para a conclusão do curso, aliado ás cobranças de publicações em periódicos e término da dissertação, constituem uma dificuldade que reflete na escrita, porquanto a pressão é um fator limitante. Para os discentes analisados nesse trabalho a elaboração de capítulos de livros é operação mais fácil, quando se compara a periódicos, pois a estrutura rígida de avaliação desses magazines científicos é um entrave para a escrita e submissão de artigos (BATISTA, NOBREGA-THERRIEN E ALMEIDA, 2009).

Quando analisamos as publicações em periódicos, novamente um curso da área da saúde se sobressai - o MA em Cuidados Clínicos em Enfermagem e Saúde - pois o grupo IC produziu a média de quase quatro artigos por aluno IC $(3,78)$. É sabido que, nos periódicos de alguns setores do saber (saúde é área de um deles), é permitida a autoria de um artigo por até seis autores. Essa prática pode facilitar o que chamamos de publicações em rede, acordo entre os autores que rendem mais produtos para os envolvidos. É algo bem diferente dos periódicos das Ciências Humanas, onde o máximo de autores permitidos não passa de três por artigo.

Em cinco dos 12 cursos analisados nessa etapa, o grupo NIC teve média maior do que o grupo IC no quesito publicação em periódico. Nos cursos MA em Administração, MA em Serviço Social Trabalho e Questão Social, MA em História e Culturas, MA em Linguísti- 
ca Aplicada e MA em Ciências da Computação, levamos em consideração a qual o periódico os discentes submetiam seus artigos. Utilizamos a classificação elaborada pela CAPES.

O Qualis-Periodícos é planejado por área de avaliação e seu conceito pode variar de acordo com as diversas áreas. Os periódicos são classificados do melhor para o pior, sendo que A1 significa o de maior peso, seguido por A2, B1, B2, B3, B4, B5 e C com nenhum peso para avalição do docente pesquisador e ao programa a que este pertence. Distribuímos os resultados de acordo com o Qualis-Periodícos escolhido pelos discentes para publicação de seus artigos, conforme está no gráfico a seguir.

Gráfico 3 - Comparação de Qualis Periódicos entre grupo IC e NIC pertencentes aos cursos de mestrado acadêmico da UECE sediados em Fortaleza - turmas 2015

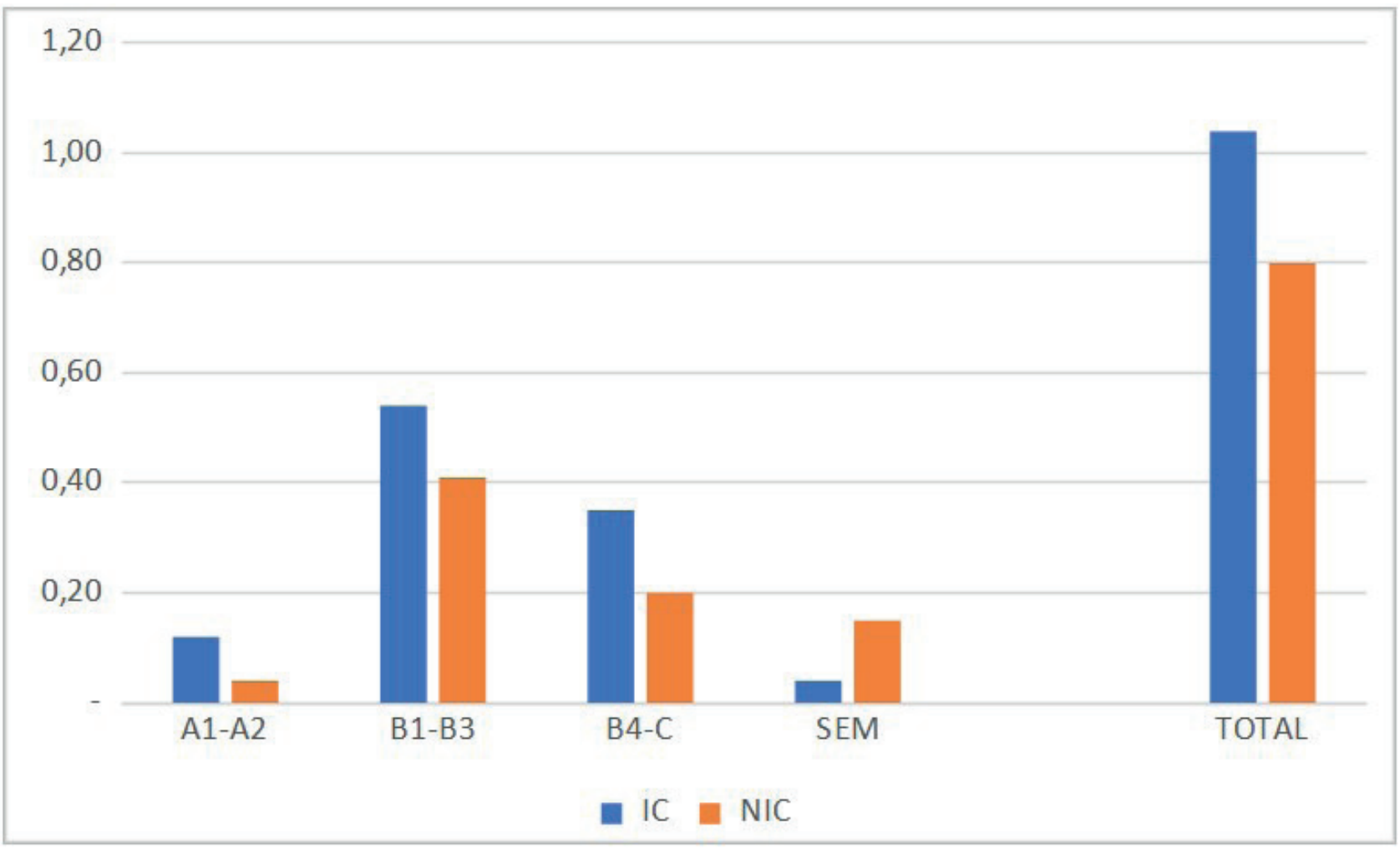

Fonte: Elaboração própria, com base no Currículo Lattes dos discentes analisados.

Fica evidenciado no gráfico 3 o fato de que, nos estratos de maior qualidade de veiculação - A1 e A2, são predominantes as publicações do grupo IC (com uma média de 0,12 para IC e 0,04 para NIC). O mesmo também ocorre no estrato B1 a B3 (a média de 0,54 para IC e 0,41 para NIC), como também no estrato de menor qualidade B4 - C (com média de 0,35 para IC e 0,15 para NIC). Alguns periódicos não estavam cadastrados no sistema de avaliação. Para essa ocorrência, a CAPES (2016) aponta dois motivos: (i) a revista não foi indicada por nenhum programa de pós-graduação como veículo para divulgação de suas pesquisas; (ii) pode ter sido informado por algum programa, mas foi classificado como "não periódico" com apoio em critérios preestabelecidos pelos documentos de cada área. 
Nesse sentido, periódicos sem classificação podem não ter excelência na comunidade científica. Nas publicações em periódicos dessa natureza foi verificado maior percentual de discentes do grupo NIC com relação aos IC (com média de 0,04 para IC e 0,15 para NIC). No total de publicações em periódicos, vemos a média de 1,04 produto para discente IC e 0,80 para NIC.

Para proporcionar uma visão geral dos achados, elaboramos um gráfico sem a divisão por cursos, contendo apenas os valores totais, obedecendo as classificações IC e NIC, e, conforme já discutido, dos seis quesitos analisados, em apenas um (apresentação de trabalho), o grupo NIC se sobrepôs ao IC. Vejamos gráfico a seguir.

Gráfico 4 - Distribuição de produção científica entre discentes IC e NIC dos cursos de mestrado acadêmico UECE sediados em Fortaleza turmas 2015

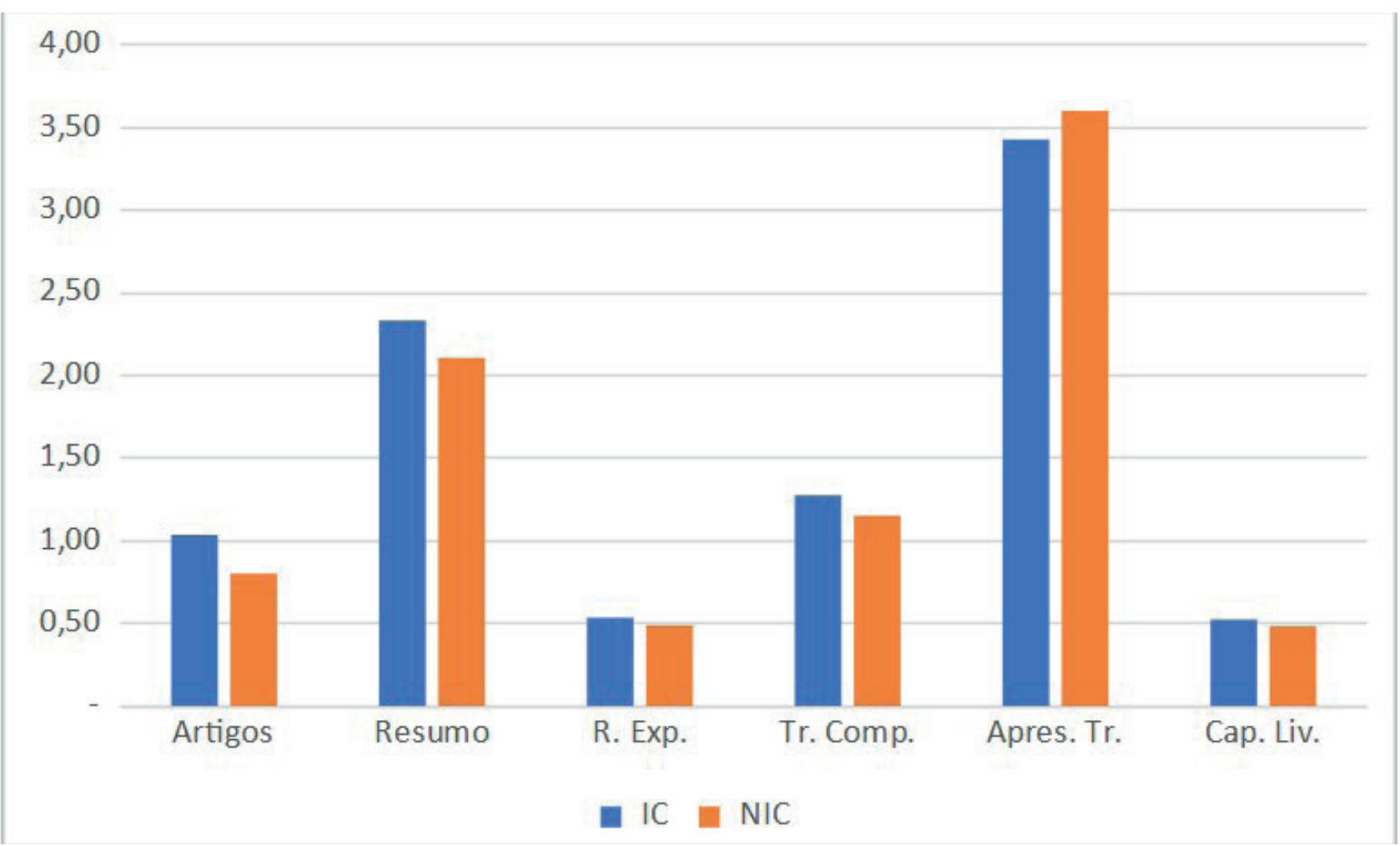

Fonte: Elaboração própria, com base no Currículo Lattes dos discentes analisados.

Nobrega-Therrien e Andrade (2009) entendem que a pós-graduação é o local para a produção do conhecimento e, consequentemente, sua divulgação. Chamam atenção, no entanto, para a noção de que a fim de se efetivarem boas pesquisas, impõem-se um amadurecimento e a apropriação conceitual do objeto de pesquisa. Para que isso ocorra, entretanto, o tempo é fator crucial. O encurtamento dos cursos de pós-graduação é de certo modo, recente, pois aconteceu nos anos 2000. Essa realidade exige nova organização, a disposição e - claro - a preparação do discente para esta produção, o que vamos encontrar com maior frequência em egressos de IC. 
Não pretendemos defender aqui o ponto de vista de que a pós-graduação deva necessariamente ser destinada ou voltada para privilegiar ou receber exclusivamente os egressos de IC, uma vez que essa formação diferenciada não contempla ou abre a oportunidade para a participação de todos os discentes na graduação. É uma discussão, digamos complexa, pois envolve também variáveis outras, como a falta de amadurecimento ou experiência do discente que vem da graduação e se insere em seguida em um curso de pós-graduação. A ausência de experiência no mercado de trabalho é um fator limitante para o desenvolvimento dos saberes da experiência, tão importantes para níveis de reflexividade crítica, o que comumente é encontrado em discentes de mais idade, mais amadurecidos.

Evidenciamos também, a importância e a abertura de oferta desse espaço de formação diferenciada que o IC promove, extensivo a todos os alunos quando de seu curso na graduação. A integração ensino e pesquisa ou ensino com e na pesquisa contribui não somente para ensinar como também a fim de desenvolver um trabalho cientifico, mas, como assinala Demo (2011), desmistificando o conceito resumido e estereotipado de pesquisa.

[...] tendo em vista que [a pesquisa] aparece naturalmente - porque necessariamente - na formação histórica do sujeito social competente. Essa competência deve ser formal (domínio científico-tecnológico) e política (construção da cidadania), onde dialogar crítica e produtivamente com a sociedade e com a realidade é a própria demonstração da competência e da cidadania (p.43)

Para autores como Farias et al (2014), esta articulação da pesquisa com o ensino desenvolve no discente uma atitude investigativa, tão necessária as transformações tecnológicas, cientificas e de toda ordem, pelas quais passa a sociedade nos dias de hoje e que requer uma formação para emancipação, a cidadania. Com efeito, para nós, a formação diferenciada é evidenciada, pois traz implicações positivas, no caso, quanto à aprovação em processos seletivos na pós-graduação, a produção e publicação durante a realização do curso.

\section{CONCLUSÕES:}

\section{PROCESSO SELETIVO}

Neste estudo, contamos com a participação de 13 cursos sediados na UECE Fortaleza, o MA em Recursos Naturais e o MA em Ciências da Computação não enviaram os documentos solicitados, tampouco disponibilizaram esses dados em sítios de internet. Respondendo ao objetivo de determinar as diferenças no processo seletivo em curso de mestrado acadêmico com relação aos inscritos e aprovados com ou sem formação diferenciada em pesquisa, constatamos, no que concerne ao processo seletivo realizado em 2014 para formar as turmas de Mestrado Acadêmico (MA) da UECE do ano de 2015; conforme as descrições seguintes: 
- houve grande variação no número de candidatos inscritos em cada curso, variando de dez candidatos no MA em Ciências Veterinárias a 218 inscritos no MA em Educação;

- dentre os postulantes inscritos, comprovamos o predomínio de alunos NIC sobre os IC na soma de candidatos de todos os cursos. Esse predomínio se repete na análise individual de dez dos 12 cursos, sendo a proporção de alunos NIC maior entre os candidatos do MA em Serviço Social, Trabalho e Questão Social (com $87,8 \%$ de candidatos NIC) e menor no MA em Ciências Veterinárias (com a surpreendente proporção de apenas $10 \%$ sem experiência com IC);

- analisando apenas os inscritos aprovados, foi possível determinar a composição das turmas pelos grupos IC e NIC. Em quatro dos 13 cursos analisados, a turma formada foi composta por mais discentes IC do que NIC: MA em Ciências Veterinárias (100\%, seis de seis discentes), MA em Nutrição e Saúde $(76,92 \%$, dez de 13 discentes), MA em Geografia (55,56\%, dez de 18 discentes) e MA em Filosofia (53,33\%, oito de 15 discentes);

- com relação aos candidatos aprovados na seleção de 2014 e que, portanto, compuseram as turmas 2015 dos cursos pesquisados, divisamos o fato de que, em todos os cursos analisados neste estudo, os discentes IC obtiveram as maiores taxas de aprovação se comparados com os do grupo NIC.

- quatro cursos (MA em Filosofia, MA em Educação, MA em Saúde Coletiva e MA em Cuidados Clínicos em Enfermagem e Saúde) disponibilizaram dados referentes às etapas da seleção para o mestrado. Nesses foi possível perceber a diferenciação dos discentes em cada etapa. Assim sendo, os discentes IC têm maiores números de aprovação em todas as etapas da seleção (prova escrita, análise de projeto, análise de currículo e entrevista). Exceto no quesito projeto no MA em Cuidados Clínicos em enfermagem e Saúde, mais estudos seriam necessários para elucidar esse aspecto;

- por fim, ao analisar a composição das turmas formadas por estas seleções, constatamos que, em quatro dos 13 cursos analisados, a turma formada foi composta por mais discentes IC do que NIC, e nos nove cursos restantes, embora os discentes NIC fossem maioria, a proporção de alunos do grupo IC aprovados aumentou em relação ao quantitativo de alunos IC candidatos.

Com base em nossos achados, podemos inferir que a maior predominância de alunos NIC entre os candidatos de pós-graduação é uma consequência natural do fato de que a maioria dos alunos de graduação não tenham tido a oportunidade de se inserir em atividades de IC, uma vez que, como discutimos no capítulo propedêutico, menos de $5 \%$ dos discentes de graduação da UECE têm essa oportunidade. 
Por outro lado, podemos concluir que estes poucos alunos com experiência em IC exprimem vantagens na aprovação nos processos seletivos para mestrado, uma vez que as taxas de aprovação são sempre maiores do que as de alunos NIC, independentemente do curso pretendido. Poder-se-ia, contudo, questionar se essa maior taxa de aprovação de alunos IC não seria uma consequência exclusiva do fato de eles terem um currículo maior, ou, então, por serem beneficiados de maneira indireta por terem um projeto de pesquisa já inserido na linha investigativa de seus orientadores. O fato, porém, de os alunos IC registrarem taxas melhores em todas as etapas da seleção de todos os cursos com informações disponíveis para nosso estudo, aponta para a existência de uma formação diferenciada que os capacita para que se sobressaiam nas provas escritas, entrevistas, análises de projetos e avaliação curricular, culminando na aprovação geral.

Por conseguinte, podemos concluir que, ao menos no concernente ao nosso universo delimitado pela UECE, maiores investimentos em Iniciação Científica com ampliação das oportunidades para mais alunos de graduação devem levar a maior procura desses estudantes pelos cursos de pós-graduação, elevando os níveis de concorrência das seleções, e aumentando a proporção de alunos IC, não só entre os candidatos, mas, principalmente, entre os aprovados.

\section{PRODUÇÃO CIENTIFICA}

Nesta etapa da pesquisa, contamos com a participação de 13 cursos, pois o MA em Recursos Naturais e o MA em Filosofia não enviaram os documentos solicitados nem disponibilizaram esses dados em sítios de internet. Malgrado o MA em Ciências Veterinárias ter enviado seus documentos oficiais, optamos por não incluir os dados por não conter discentes do grupo NIC na turma. Assim, nessa etapa há 12 cursos analisados.

Com relação ao objetivo que nos propomos responder, relacionado a Mapear a produção científica de estudantes egressos e não egressos de IC no mestrado acadêmico durante o período do curso, inferimos uma série de resultados, que relacionamos a seguir, respeitantes aos quesitos resumo simples, resumo expandido, trabalho completo, apresentação de trabalho, capítulo de livro e produção em periódico. Analisamos os dados sob duas formas:

- pela divisão IC e NIC por cada curso e

- pela divisão IC e NIC apenas, independentemente do curso de origem.

A seguir estão descritos nossos achados relativos à produção científica de discentes dos cursos de MA da UECE - turmas compostas em 2015:

- com relação aos resumos, em sete dos 12 cursos analisados, o grupo IC teve média maior de produtos. Chama-nos a atenção os dois cursos da área da saú- 
de, o MA em Cuidados Clínicos em Enfermagem e Saúde e MA em Saúde Coletiva, nos quais vemos significativa diferença com relação aos demais cursos; e o grupo NIC foi responsável pela maior parte de produção deles;

- os discentes dos 12 cursos estudados mantêm média baixa de publicações de resumos expandidos, abaixo de dois no período de mestrado;

- com relação à apresentação de trabalhos em cinco dos 12 cursos estudados, o grupo NIC manteve média total maior do que o IC, no MA em Física Aplicada, no MA em Educação, no MA em Administração, no MA em História e Culturas e no MA em Linguística Aplicada. Esse quesito foi o único em que a média total (sem divisão por cursos) do grupo NIC foi maior do que a média do grupo IC;

- no concernente a capítulos de livros, o curso único cujo grupo NIC teve média maior foi o MA em Ciências da Computação, ao passo que nos demais, o grupo IC se sobressaiu. Vale ressaltar ainda, o desempenho dos discentes do MA em Saúde Coletiva, com média de três capítulos de livros por grupo IC;

- quando analisamos as publicações em periódicos, novamente um curso da saúde de sobrepôs aos demais - o MA em Cuidados Clínicos em Enfermagem e Saúde - que produziu a média de quase quatro artigos por discente IC $(3,78)$;

- inferimos, de posse destes resultados de publicação em periódicos, que o grupo IC tem maiores médias de produtos em veículos de estratos $A 1, A 2, B 1, B 2, B 3$, B4, B5 e C. O grupo NIC tem maiores médias de publicações em periódicos sem Qualis (veículos sem indexação na comunidade cientifica, segundo avaliação da CAPES); e

- Dos seis quesitos analisados neste estudo, apenas no quesito apresentação de trabalho o grupo NIC se sobrepôs ao grupo IC.

É sabido que congressos e periódicos têm normas diferentes, definidas com base nas áreas de conhecimento de origem. Na saúde, por exemplo, é comum periódicos aceitando submissões de artigos de mais de seis autores, algo bem diferente do terreno das Ciências Humanas e Sociais, em que o máximo permitido são três autores por produto publicado, posição que facilita a publicação de mais pesquisadores e um só produto. Assim sendo, isto nos leva a inferir que esse motivo é configurado, sobretudo, no expressivo número de publicações dos dois cursos da saúde citados, quando comparados com os demais.

O período de 24 meses do curso de mestrado é intenso, pois se deve conciliar as disciplinas obrigatórias e suas demandas, a elaboração do projeto de qualificação e a dissertação, as demandas de grupos de pesquisas (quando os discentes estão inseridos), sem falar das atribuições profissionais e membros familiares. Assim, a produção cientifica vai sendo postergada ou deixada em segundo plano; sem se falar nos receios e bloqueios dos discentes para submeter trabalhos em periódicos, em virtude da rigidez de normas e insegurança pela avaliação dos editores (BATISTA, NOBREGA-THERRIEN E ANDRADE 2009). 
À vista destes achados, constatamos que a experiência obtida pelos discentes egressos de IC contribuiu significativamente na formação para o desenvolvimento das etapas da pesquisa e, evidentemente, forneceu elementos que facilitam sua vivência no ambiente de pesquisa da pós-graduação. Lembramos que, no entendimento de Pereira e Andrade (2008) para ensinar a pesquisar é necessário um fazer diário próximo ao orientador. Para as autoras ensinar a pesquisar é um "trabalho artesanal" (PEREIRA; ANDRADE, 2008, p. 160) que vai muito além do ensinamento de técnicas metodológicas, e que o ambiente dos grupos de pesquisas que os discentes de programas de IC frequentaram forneceu, além do aprendizado de técnicas de pesquisa, o desenvolvimento uma base epistemológica nesse discente, e essas atividades são permeadas por discussões que estimulam a reflexividade das e nas ações, portanto, formando um profissional diferenciado no modelo preconizado por Schón (2000). 


\section{REFERÊNCIAS}

BATISTA, Fátima Lúcia Ramos; NÓBREGA-THERRIEN, Silvia Maria; ALMEIDA, Maria Irismar de. Ensino, pesquisa e a produção do conhecimento: desafio para os alunos de cursos de pós-graduação. In: NÓBREGA-THERRIEN, Silvia Maria; ALMEIDA, Maria Irismar; ANDRADE, João Tadeu. Formação diferenciada: a produção de um grupo de pesquisa. Fortaleza, CE: EdUECE, 2009. p. $163-175$.

BIANCHETTI, Lúcidio. O processo da escrita: elementos inibidores e facilitadores. In: BIANCHETTI, Lucídio; MEKSENAS, Paulo. A trama do conhecimento: teoria, método e escrita em ciências e pesquisa. Campinas: Papirus, 2008. p. 86 - 103.

COORDENAÇÃO DE APERFEIÇOAMENTO DE PESSOAL DE NÍVEL SUPERIOR. Sobre avaliação de cursos. 2016. Disponível em: <http://www.capes.gov.br/acessoainformacao/perguntas-frequentes/avaliacao-da-pos-graduacao/7421-sobre-avaliacao-de-cursos>. Acesso em: 23 out. 2016.

COSTA, Airton. 0 processo de formação de pesquisadores: análise do programa de iniciação científica da Universidade Federal de Santa Catarina no período de 1990 a 2012. 2012. 204f. Dissertação (Mestrado Acadêmico em Ciências da Informação) - Programa de Pós-graduação em Ciência da Informação, Universidade Federal de Santa Catarina, Florianópolis, 2012.

DEMO, Pedro. Pesquisa: princípio científico e educativo. 14. ed. São Paulo: Cortez, 2011.

FARIAS, Isabel Maria Sabino et al. A docência universitária sob o prisma da integração ensino e pesquisa. Teresina: EDUFPI, 2014.

FAZENDA, Ivani Catarina Arantes. Dificuldades comuns entre os que pesquisam educação. In: FAZENDA, Ivani Catarina Arantes (Org.). Metodologia da pesquisa educacional. São Paulo: Cortez, 2010. p.15- 22.

FERREIRA, Sara Regina; MORRAYE, Monica Andrade. Perfil dos mestres de um programa de pós-graduação em promoção da saúde: características e percepções sobre o curso. Revista Brasileira de Pós-Graduação, Brasília, v. 10, n. 22, p. 1.085-1.107, 2013.

GEOCAPES. Sistema de informações georreferenciadas. 2017. Disponível em: <http://geocapes.capes.gov.br/geocapes2/>. Acesso em: 17 abr. 2017.

LIMA, Luciana Gasparotto Alves de. A influência da iniciação científica sobre a pós-graduação: um estudo de caso sobre tempo, idade de titulação e produção científica. 2016. 47f. Dissertação (Mestrado Acadêmico em Ciências: Química da Vida e da Saúde) - Programa de Pós-Graduação Educação em Ciências: Química da Vida e da Saúde, Universidade Federal do Rio Grande do Sul, Porto Alegre, 2016.

LÜDKE, Menga et al. O que conta como pesquisa? São Paulo: Cortez, 2009.

LÜDKE, Menga; RODRIGUES, Priscila Andrade Magalhães; PORTELLA, Vanessa Cristina Máximo. O mestrado como via de formação de professores da educação básica para a pesquisa. Revista Brasileira de Pós-Graduação, Brasília, v. 9, n. 16, p. 59 - 83, 2012. 
NÓBREGA-THERRIEN, Silvia Maria; ALMEIDA, Maria Irismar; ANDRADE, João Tadeu. Formação diferenciada: a produção de um grupo de pesquisa. Fortaleza: EdUECE, 2009.

NÓBREGA-THERRIEN, Silvia Maria; ANDRADE, Laurinete Sales. A pesquisa na pós-graduação: possibilidades e limites na construção do conhecimento. In: NÓBREGA-THERRIEN, Silvia Maria; ALMEIDA, Maria Irismar; ANDRADE, João Tadeu. Formação diferenciada: a produção de um grupo de pesquisa. Fortaleza, CE: EdUECE, 2009. p. 45 - 59.

NÓBREGA-THERRIEN, Silvia Maria; CRUZ, Helania do Prado; ANDRADE, Laurinete Sales. O ensino da pesquisa: percepções de alunos de graduação dos cursos da área da saúde. In: NÓBREGA-THERRIEN, Silvia Maria; ALMEIDA, Maria Irismar; ANDRADE, João Tadeu. Formação diferenciada: a produção de um grupo de pesquisa. Fortaleza, CE: EdUECE, 2009. p. $45-59$.

OLIVEIRA, Andressa Maia de. Contribuições do programa institucional de bolsas de iniciação científica (PIBIC) para a formação do aluno de psicologia. 2013. 101f. Dissertação (Mestrado Acadêmico em Psicologia) - Programa de Pós-graduação em Psicologia, Universidade Federal do Rio Grande do Norte, Natal, 2013.

PEREIRA, Gilson Ricardo de Medeiros; ANDRADE, Maria da Conceição Lima. Aprendizagem científica: experiência com grupo de pesquisa. In: BIANCHETTI, Lucídio; MEKSENAS, Paulo. A trama do conhecimento: teoria, método e escrita em ciências e pesquisa. Campinas: Papirus, 2008. p. 86 - 103.

SCHON, Donald. Educando o profissional reflexivo: um novo design para o ensino e aprendizagem. Porto Alegre: Artes Médicas Sul, 2000.

SILVA, Silvina Pimentel. Histórias de formação em grupos de iniciação científica: trajetórias da UECE e da UFC (1985 a 2005). 2008. 212f. Tese (Doutorado em Educação) - Programa de Pós-Graduação em Educação, Universidade Federal do Ceará, Fortaleza, 2008.

UNIVERSIDADE ESTADUAL DO CEARÁ. Pela $\mathbf{6}^{\text {a }}$ vez, UECE é a melhor estadual do Norte, Nordeste e Centro-Oeste. 2016a. Disponível em: <http://www.uece.br/uece/index.php/noticias/93793-2016-09-21-11-42-24>. Acesso em: 22 nov. 2016.

UNIVERSIDADE ESTADUAL DO CEARÁ. Pró-Reitoria de Pós-Graduação e pesquisa. Programa institucional de bolsas de iniciação científica. 2016b. Disponível em: <http://www.propgpq.uece. br/index.php?option=com_content\&view=article\&id=74\&ltemid=146>. Acesso em: 23 mai. 2016.

UNIVERSIDADE ESTADUAL DO CEARÁ. Pró-Reitoria de Pós-Graduação e Pesquisa. Cursos de mestrado e doutorado: pós-graduação stricto sensu. 2016c. Disponível em: <http://www.propgpq. uece.br/index.php?option=com_content\&view=article\&id=67\&ltemid=142>. Acesso em: 16 out. 2016.

UNIVERSIDADE ESTADUAL DO CEARÁ. Programa de Pós-Graduação em Educação. Processo seletivo. 2017. Disponível em: < http://www.uece.br/ppge/index.php/processo-seletivo>. Acesso em: 18 jul.2017.

VELLOSO, Jacques; VELHO, Léa. Mestrandos e doutorandos no país: trajetórias de formação. Brasília: Fundação Coordenação de Aperfeiçoamento de Pessoal de Nível Superior, 2001.

VOLPATO, Gilson Luiz. Ciência: da filosofia à publicação. Botucatu: Tipomic, 2004. 